Article

\title{
Optimized Dyeing Process for Enhancing the Functionalities of Spent Coffee Dyed Wool Fabrics Using a Facile Extraction Process
}

\author{
Jihyun Bae ${ }^{1}$ and Kyung Hwa Hong ${ }^{2, *}$ \\ 1 College of Human Ecology, Department of Clothing and Textiles, Hanyang University, \\ Seoul 04763, South Korea; jbae2@hanyang.ac.kr \\ 2 College of Natural Science, Kongju National University, Chungnam 32588, South Korea \\ * Correspondence: hkh713@kongju.ac.kr; Tel.: 82-41-850-8305
}

Received: 1 March 2019; Accepted: 25 March 2019; Published: 28 March 2019

\begin{abstract}
Spent coffee grounds are the byproduct of coffee brewing and are generally discarded as waste. However, spent coffee has high levels of organic compounds that have multiple biological effects, including antibacterial and antioxidant activities. In this light, spent coffee grounds were tested for fabric dyeing to both functionalize as well as color the fabrics. The dyeing solution was prepared by extracting spent coffee grounds collected from a local coffee house by using a manual espresso machine. The spent coffee extract was applied to wool fabrics using a laboratory infrared dyeing machine. After the dyeing process was completed, the fabrics were mordanted with a tannic acid aqueous solution. To optimize the dyeing conditions, the times and temperatures during the process were varied, and the functionalities and other properties including color and strength of the wool fabrics dyed with the spent coffee extract were investigated. The wool fabrics dyed with the spent coffee extract were significantly colored, and the color withstands the effect of washing and light exposure. Moreover, the dyeing process with the spent coffee extract and the mordanting process with tannic acid gave the wool fabrics antibacterial and antioxidant properties.
\end{abstract}

Keywords: wool; spent coffee; tannin; dyeing; antibacterial property; antioxidant property

\section{Introduction}

Approximately 7.4 million tons of coffee is produced each year and it is the most consumed luxury table beverage in the world. Coffee is also the second most traded commodity by volume after petroleum, indicating that the economic impact of coffee is substantial [1]. In 2017 in Korea alone, approximately 26.5 billion cups of coffee were consumed. Considering the population of Korea, approximately 512 cups of coffee were consumed per person in 2017. Korea's coffee market exceeded 10 trillion KRW (ca. 8.76 billion USD) for the first time in 2017. This market size is more than three times greater than it was 10 years ago [2]. Since coffee consumption has increased so dramatically, the amount of spent coffee grounds produced after brewing coffee cannot be ignored. In contrast to the rapid growth of the coffee market, the development of efficient treatments for spent coffee grounds is difficult because there is no established system for collecting and recycling spent coffee grounds [3]. Spent coffee grounds are not just food garbage; they are also a major cause of environmental pollution since they produce a large amount of methane gas, which has an adverse effect on global warming. The effect of methane gas is assumed to be approximately 2.5 times worse than that of carbon dioxide, and the amount of carbon dioxide produced by spent coffee grounds is approximately 1.6 times more than that produced by black tea [4]. However, spent coffee grounds still contain many functional components, such as phenolic compounds, terpenes, caffeine, and Maillard reaction products. Therefore, treatment of this bio-waste by simply burying it in a landfill or incinerating it may be wasting a valuable resource. 
Our group recently conducted a study on the dyeing and finishing of cotton and wool fabrics by using spent coffee extract prepared by the extraction method suggested by Mussatto et al. [5]. This method was reported to be effective for extracting active components from spent coffee grounds. It involves placing the spent coffee grounds in a $60 \%$ aqueous methanol solution and shaking the solution for $60 \mathrm{~min}$ in a water bath at $60{ }^{\circ} \mathrm{C}[6,7]$. The study showed that the fabrics treated with the spent coffee extract displayed a good antioxidant capacity and significant antibacterial activity, especially towards Gram-positive bacteria. In particular, the spent coffee extract showed strong color fastness in the fibers containing amide groups in their polymers (such as those found in wool fiber). This strong color manifestation indicates that spent coffee grounds may be an effective material for fiber dyeing and functionalization. Recently, we found that higher concentrations of effective components such as total phenolics and total condensed tannins are present in the spent coffee extract prepared by a typical espresso machine than in the extract prepared via a methanolic extraction [5-7]. Thus, machine extraction may be a good extraction method for fiber dyeing because it does not require methanol, a toxic solvent, which would need to be evaporated from the extract for fabric applications such as dyeing. In the present study, spent coffee extract prepared by using an espresso machine was used for wool dyeing, and the optimal dyeing conditions were investigated. In addition, tannic acid was used as a mordant in the fabric to improve its functionalities and the coloring effect of the spent coffee extract on the wool fabric. In addition, tannic acid is well known as an eco-friendly mordant and many researchers have been using it for attaining high quality natural dyeing along with imparting multifunctional properties from textile dyes $[8,9]$.

\section{Materials and Methods}

\subsection{Sample Material and Chemicals}

A commercially available scoured wool fabric (ISO 105-F01; plain woven $125 \mathrm{~g} / \mathrm{m} 2$ ) was prepared (Testfabrics Inc. West Pittston, PA, USA). Spent coffee grounds (Coffea arabica L.) were supplied from a local coffee house in Gongju, Korea. Folin-Ciocalteu reagent, gallic acid $(\geq 97 \%)$, vanillin $(99 \%),(+)$-catechin hydrate $(\geq 98 \%)$, potassium iodate, sodium bicarbonate, formic acid, acetonitrile, trigonelline, protocatechuic acid, tannic acid (ACS reagent, Mw: 1701.20), chlorogenic acid, and caffeine were purchased from Sigma-Aldrich (St. Louis, MO, USA). Free radical DPPH (1,1-diphenyl-2-picrylhydrazyl) was purchased from Calbiochem (San Diego, CA, USA). All reagents were used as received without further purification.

\subsection{Extraction of Spent Coffee Grounds to Prepare the Dyeing Solution}

A manual espresso machine (Gaggia Gran Prestige, Milano, Italy) at a pump pressure of 15 bar was utilized for extracting dying solution from the spent coffee. The extract was used as a stock solution for the dyeing of fabrics in this study.

\subsection{Dyeing Process}

Wool fabrics were cut into $30 \mathrm{~cm} \times 30 \mathrm{~cm}$ pieces, and each piece was immersed in a vessel containing the stock solution of the spent coffee extract (bath ratio $=1: 30$ ). A laboratory infrared (IR) dyeing machine (Daelim Starlet Co., Ltd; Gyeonggi-do, Korea) was used for the dyeing process. The temperature of the dyeing bath was gradually increased (ca. $3^{\circ} \mathrm{C} / \mathrm{min}$ ) up to the designated temperature $\left(60,90\right.$, and $\left.120^{\circ} \mathrm{C}\right)$, and then that temperature was maintained while the vessels were rotated at $45 \mathrm{rpm}$ for the designated dyeing time (30,60, 90, and $120 \mathrm{~min})$. The dyed wool fabrics were thoroughly rinsed with deionized water and squeezed using a padder to obtain $100 \mathrm{wt} \%$ of a specified wet pick-up rate. 


\subsection{Mordanting Process}

The wool fabrics dyed with the spent coffee extract were subsequently mordanted as follows. After being squeezed with a padder, the damp wool fabrics were put into vessels containing a $1 \mathrm{wt} \%$ tannic acid aqueous solution (bath ratio $=1: 30$ ). The vessels were then shaken at $130 \mathrm{rpm}$ for $60 \mathrm{~min}$ at $85^{\circ} \mathrm{C}$. The wool fabrics were next thoroughly rinsed with deionized water and dried in a convection oven at $60^{\circ} \mathrm{C}$.

\subsection{Analysis of the Spent Coffee Extract}

The antioxidant compounds in the spent coffee extract were analyzed by high-performance liquid chromatography (HPLC) using a diode array detector (Agilent Technologies, 1260 Infinity, Waldbronn, Germany). A Kinetex 5- $\mu \mathrm{m}$ C18 column $(150 \mathrm{~mm} \times 4.6 \mathrm{~mm}$ i.d., Phenomenex, Torrance, CA, USA) was employed at $40{ }^{\circ} \mathrm{C}$. The antioxidant compounds were separated by a gradient mobile phase consisting of (A) $0.1 \%$ formic acid and (B) acetonitrile at a flow rate of $1 \mathrm{~mL} / \mathrm{min}$. The gradient was programmed as follows: $0-10 \mathrm{~min}, 15 \%-37 \% \mathrm{~B} ; 5-10 \mathrm{~min}, 37 \%-80 \% \mathrm{~B} ; 10-12 \mathrm{~min}, 80 \%-100 \%$ $\mathrm{B}$; and $12-13 \mathrm{~min}, 100 \%-15 \% \mathrm{~B}$. The major antioxidant compounds were identified based on the similarities between their experimental retention times and ultraviolet-visible (UV-Vis) spectra and those of pure authentic standards (trigonelline, gallic acid, chlorogenic acid, and caffeine). The total phenolic content in the spent coffee extract was measured by the colorimetric method described by Singleton and Rossi [10]. Folin-Ciocalteu reagent $(2.5 \mathrm{~mL}$, previously diluted with water 1:10, v/v) and $2 \mathrm{~mL}$ of $75 \mathrm{~g} / \mathrm{L}$ aqueous sodium carbonate were added to $0.5 \mathrm{~mL}$ of an aqueous solution of the extract. The mixture was kept at $50{ }^{\circ} \mathrm{C}$ for $5 \mathrm{~min}$, and after cooling, the absorbance was measured at $760 \mathrm{~nm}$ (Biomate5 spectrophotometer, Thermo, Waltham, MA, USA). The total phenolic content was calculated in terms of gallic acid equivalents (GAE) from the calibration curve of gallic acid standard solutions (2-40 $\mu \mathrm{g} / \mathrm{mL}$ ) and is expressed as $\mathrm{mg}$ gallic acid equivalent (GAE)/mg of extract (on a dry basis). The total tannin content in the spent coffee extract was determined by the vanillin/ $\mathrm{HCl}$ method described by Broadhust and Jones [11] with some modifications. An aliquot of the extracts (1 mL) was added to the vanillin reagent $(2 \mathrm{~mL})$, which had been prepared by dissolving vanillin in methanol $(0.5 \%, \mathrm{w} / \mathrm{v})$. Aqueous $\mathrm{HCl}(2 \mathrm{~mL}, 4 \%, \mathrm{v} / \mathrm{v})$ was added to the mixture, and then the mixture was incubated in the dark. The absorbance was measured at $500 \mathrm{~nm}$ after $20 \mathrm{~min}$ of incubation. Different concentrations (500-3000 $\mu \mathrm{g} / \mathrm{mL}$ ) of (+)-catechin standards were used to calculate the condensed tannin content. The total tannin content was expressed as $\mathrm{mg}$ of tannic acid equivalents (TAE) $/ \mathrm{mL}$. All samples were analyzed in triplicate, and the mean value was calculated.

\subsection{Characteristics of the Fabrics Dyed with the Spent Coffee Extract}

Color properties, in terms of the $\mathrm{L}^{*}, \mathrm{a}^{*}$, and $\mathrm{b}^{*}$ values, and color differences, $\Delta \mathrm{E}$, of the dyed fabrics were investigated using a spectrophotometer (CM-2500d, Konica Minolta, Inc., Osaka, Japan). The color strength $(\mathrm{K} / \mathrm{S})$ values were assessed using the Kubelka-Munk Equation (1):

$$
\mathrm{K} / \mathrm{S}=\frac{(1-\mathrm{R})^{2}}{\mathrm{R}}
$$

In the above equation, $\mathrm{R}$ is the decimal fraction of the reflectance of the dyed fabric.

Color fastness was investigated as follows: color fastness to washing (ISO 105 C06: 2010, A2S, 30 min mechanical wash at $40 \pm 2{ }^{\circ} \mathrm{C}$ in $0.4 \%$ European Colorfastness Establishment (ECE) reference detergent and $0.1 \%$ sodium perborate tetrahydrate solution with 10 steel balls); color fastness to light (ISO 105 B02: 2014, Xenon-arc lamp, blue scale). All tests were conducted at least in triplicate for all samples.

The shrinkage rate of dyed fabrics was determined based on the fabric count values measured via fabric analyzing glass, and calculated using Equation (2): 


$$
\text { Shrinkage }(\%)=\frac{\mathrm{D}-\mathrm{P}}{\mathrm{D}} \times 100
$$

In the above equation, $\mathrm{D}$ and $\mathrm{P}$ represent the fabric count values of dyed fabrics and pristine fabrics, respectively.

The tensile strength of the fabrics was measured by the cut strip method (modified ASTM D5035) only in the weft direction using an Instron 5543 system (Norwood, MA, USA); $300 \mathrm{~mm} / \mathrm{min}$, gauge length: $50 \mathrm{~mm}$, specimen width: $25 \mathrm{~mm}$.

Fourier transform infrared (FT-IR) spectrometry was performed using a Spectrum 100 Optica FT-IR instrument (PerkinElmer, Waltham, MA, USA) with a resolution of $4 \mathrm{~cm}^{-1}$. The FT-IR measurements were carried out using an attenuated total reflectance (ATR) technique.

The ability of the dyed fabrics to impede microbial growth and retention was tested using Staphylococcus aureus (ATCC 6538; a Gram-positive bacterium) and Klebsiella pneumoniae (ATCC 4352; a Gram-negative bacterium) cultures according to an established protocol (KS K 0693).

$$
\text { Reduction of bacteria }(\%)=\frac{(\mathrm{B}-\mathrm{A})}{\mathrm{B}} \times 100
$$

In the above equation, A and B represent the surviving bacterial cells (colony-forming units mL-1) on the plates inoculated with the bacterial solution derived from the dyed fabric and a control solution derived from untreated fabric, respectively.

The antioxidant activity of the dyed fabrics was measured with DPPH using a previously reported method [12]. More details are presented in our previous papers [6,7]. Lower absorbances of the solutions indicated higher DPPH scavenging abilities. The DPPH scavenging ability was calculated using Equation (4).

$$
\text { DPPH } \cdot \text { scavenging activity }(\%)=\frac{\mathrm{C}-\mathrm{S}}{\mathrm{C}} \times 100
$$

In the above equation, $S$ and $C$ represent the absorbance at $517 \mathrm{~nm}$ of the sample from the dyed fabric and that of the control from the untreated fabric, respectively.

\section{Results}

\subsection{Analysis of the Components of the Spent Coffee Extract}

Four compounds were identified in the spent coffee extract by comparing their retention times and UV-Vis spectra with those of authentic standards (pure chemicals). Although a tiny peak appeared near the retention time corresponding to protocatechuic acid in Figure 1b, its UV-Vis spectrum was not identical with that of protocatechuic acid. This revealed that there is no protocatechuic acid in the spent coffee extract prepared in this research, even though the functional compound is known to exist in coffee extract [13]. The other four identified peaks were phenolic compounds (gallic acid and chlorogenic acid) and nitrogenous compounds (trigonelline and caffeine). Among the compounds identified, caffeine was the most abundant in the spent coffee extract. These results are consistent with previous studies [6]. The total phenolic content and total tannin content in the spent coffee extract were $2.63 \mathrm{~g} / \mathrm{L}(\mathrm{GAE})$ and $10.20 \mathrm{~g} / \mathrm{L}(\mathrm{TAE})$, respectively. For comparison, the total phenolic and total tannin content in the spent coffee extract prepared using methanolic method were $2.00 \mathrm{~g} / \mathrm{L}(\mathrm{GAE})$ and $0.61 \mathrm{~g} / \mathrm{L}(\mathrm{TAE})$, respectively, according to our previous study [6,7]. Therefore, it was found that all the functional compounds extracted by the espresso machine are present in much greater quantities than those extracted by the methanolic method. 


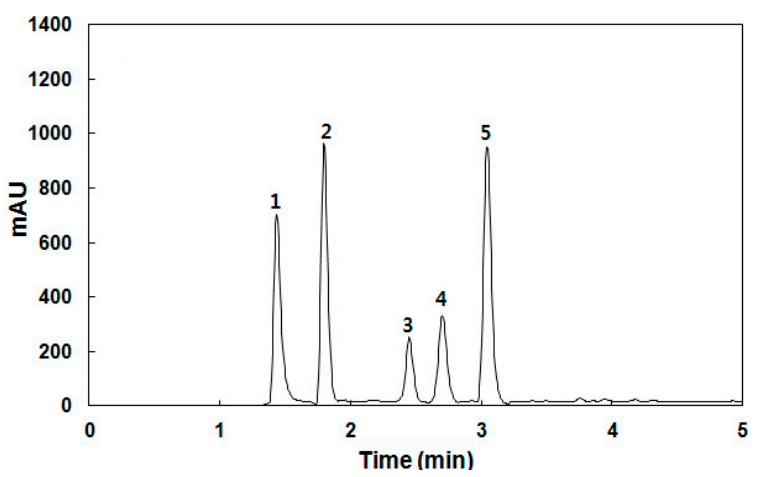

(a)

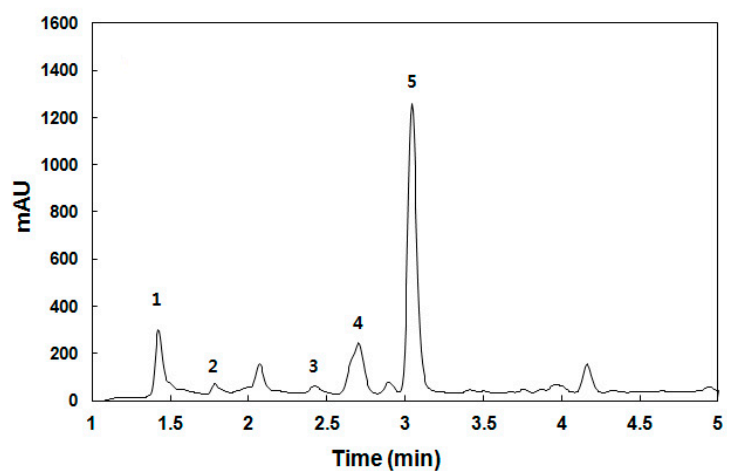

(b)

Figure 1. High-performance liquid chromatograms of standards (a) and spent coffee extract (b) at $258 \mathrm{~nm}$. 1: trigonelline; 2: gallic acid; 3: protocatechuic acid; 4: chlorogenic acid; and 5: caffeine.

\subsection{Fourier Transform Infrared (FT-IR) Spectra of the Wool Fabrics Dyed with the Spent Coffee Extract}

The FT-IR spectra of the wool fabrics dyed with the spent coffee extract and mordanted with tannic acid are shown in Figure 2. Wool fabrics are made from protein fibers containing various functional groups, such as carboxyl $(-\mathrm{COOH})$, amino $\left(-\mathrm{NH}_{2}\right)$, and hydroxyl $(-\mathrm{OH})$ groups [14]. Thus, all wool fibers displayed similar absorption bands at $3283 \mathrm{~cm}^{-1}(\mathrm{~N}-\mathrm{H}$ and $\mathrm{O}-\mathrm{H}), 2873 \mathrm{~cm}^{-1}\left(-\mathrm{CH}_{2}\right)$, $1634 \mathrm{~cm}^{-1}$ (amide I), $1512 \mathrm{~cm}^{-1}$ (amide II), and $1229 \mathrm{~cm}^{-1}$ (amide III). However, new peaks at 1312 $\mathrm{cm}^{-1}$ and $1037 \mathrm{~cm}^{-1}$ were observed in the spectra of the wool fabrics dyed with the spent coffee extract and mordanted with tannic acid. These bands are presumed to be driven by the $\mathrm{C}-\mathrm{O}$ stretching of the ester attributed to tannin in the wool fabrics dyed with spent coffee extract and mordanted with tannic acid. This is because the new bands were more intense after mordanting with tannic acid, as shown in Figure 3. Tannin is very soluble in water, and the hydrolyzable tannins break down via hydrolysis to give gallic acid, a type of phenolic compound [15-17]. Therefore, a significant amount of phenolic compounds was chemically attached to the wool fibers through the mordanting process as well.

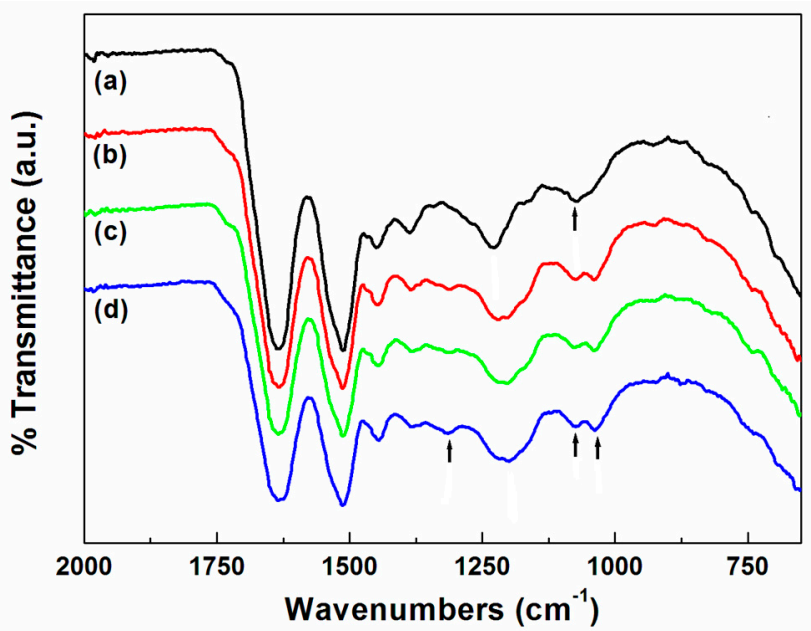

Figure 2. Fourier transform infrared-attenuated total reflectance (FT-IR-ATR) spectra of wool fabrics dyed with spent coffee extract for $60 \mathrm{~min}$ as a function of dyeing temperature (all dying samples were mordanted with $1 \mathrm{wt} \%$ tannic acid aqueous solution): (a) untreated, (b) $60^{\circ} \mathrm{C}$, (c) $90^{\circ} \mathrm{C}$, and (d) $120^{\circ} \mathrm{C}$. 


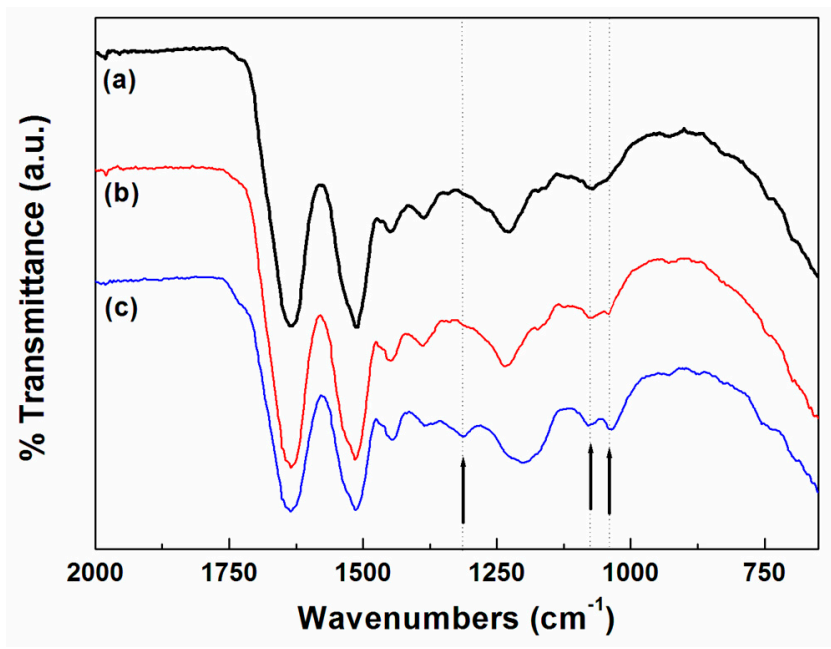

Figure 3. FT-IR-ATR spectra of wool fabrics dyed with spent coffee extract at $90{ }^{\circ} \mathrm{C}$ for $60 \mathrm{~min}$ : (a) untreated, (b) not mordanted, and (c) mordanted with $1 \mathrm{wt} \%$ tannic acid.

\subsection{Apparent Colors of the Wool Fabrics Dyed with the Spent Coffee Extract}

Dyeabilities of the wool fabrics dyed with the spent coffee extract and mordanted with tannic acid were improved overall as the dyeing time and dyeing temperature increased. In particular, dyeing temperature had a significant effect on the dyeability, while dyeing time negligibly did, as shown in Figures 4 and 5. In addition, the wool fabrics dyed with the spent coffee extract and mordanted with tannic acid showed increasing $a^{*}$ values but decreasing $b^{*}$ and $L^{*}$ values as the dyeing time and dyeing temperature increased, as shown in Table 1 . This result indicates that reddish hue became dominant but yellowish hue became faint in the wool fabrics as the dyeing time and dyeing temperature increased. It appears that the brown pigments were primarily caused by melanoidins produced during the process of roasting coffee beans. Melanoidins are brown compounds and are known to have several biological activities, such as antioxidant, antimicrobial, anticarcinogenic, anti-inflammatory, antihypertensive, and antiglycative activities. However, knowledge of melanoidins in coffee including the chemical structures is still lacking [18]. On the other hand, it was observed that mordanting with $1 \mathrm{wt} \%$ tannic acid has little effect on the color appearance of wool fabrics dyed with spent coffee extract, as shown in Table 1. To identify the levelness of wool fabrics dyed with the spent coffee extract, we investigated the color difference of two different points with at least $10 \mathrm{~cm}$ distance within each sample. Consequently, any unlevelness was not noticed in the wool fabrics dyed with the spent coffee extract.

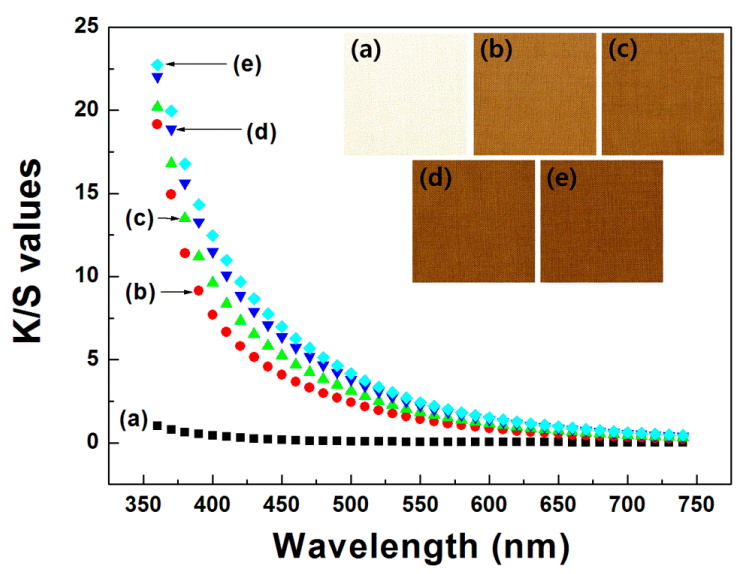

Figure 4. Color strength (K/S) values of wool fabrics dyed with spent coffee extract at $90{ }^{\circ} \mathrm{C}$ as a function of dyeing time (all dying samples were mordanted with $1 \mathrm{wt} \%$ tannic acid aqueous solution): (a) untreated, (b) $30 \mathrm{~min}$, (c) $60 \mathrm{~min}$, (d) $90 \mathrm{~min}$, and (e) $120 \mathrm{~min}$. 


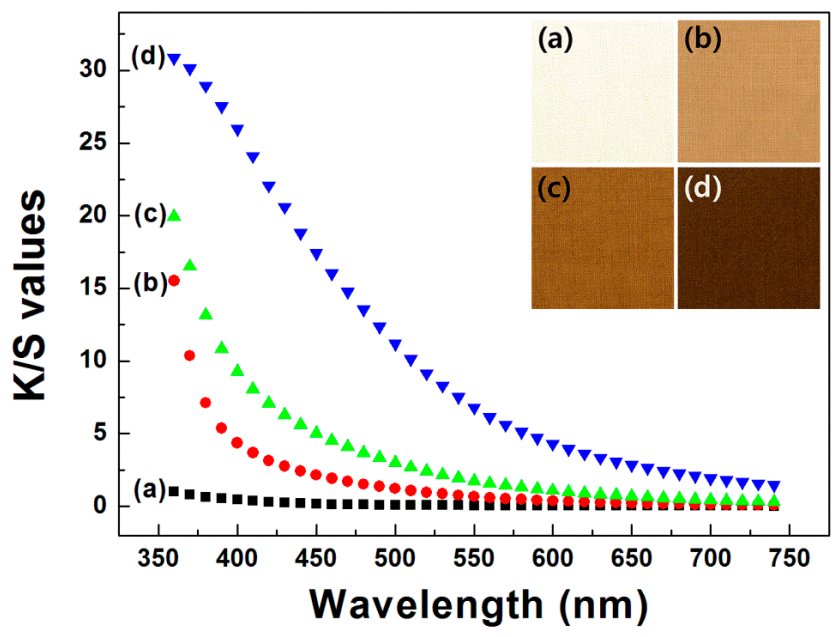

Figure 5. K/S values of wool fabrics dyed with spent coffee extract for $60 \mathrm{~min}$ as a function of dyeing temperature (all dying samples were mordanted with $1 \mathrm{wt} \%$ tannic acid aqueous solution): (a) untreated, (b) $60^{\circ} \mathrm{C}$, (c) $90^{\circ} \mathrm{C}$, and (d) $120^{\circ} \mathrm{C}$.

Table 1. Color values of wool fabrics dyed with spent coffee extract and mordanted with $1 \mathrm{wt} \%$ tannic acid aqueous solution.

\begin{tabular}{|c|c|c|c|c|c|}
\hline \multicolumn{2}{|c|}{ Dyeing Conditions } & \multirow{2}{*}{$\mathbf{L}^{*}$} & \multirow{2}{*}{$a^{*}$} & \multirow{2}{*}{$\mathbf{b}^{*}$} & \multirow{2}{*}{$\Delta \mathrm{E}$} \\
\hline Temperature $\left({ }^{\circ} \mathrm{C}\right)$ & Time (min) & & & & \\
\hline \multicolumn{2}{|c|}{ Untreated } & 86.54 & -0.59 & 12.68 & - \\
\hline \multicolumn{2}{|c|}{ Only mordanted } & 85.02 & 1.04 & 12.96 & 2.24 \\
\hline \multirow{4}{*}{90} & 30 & 54.12 & 9.59 & 27.40 & 37.03 \\
\hline & 60 & 50.29 & 9.82 & 26.88 & 40.30 \\
\hline & 90 & 47.40 & 10.12 & 26.62 & 42.91 \\
\hline & 120 & 46.08 & 10.19 & 26.49 & 44.09 \\
\hline 60 & \multirow{3}{*}{60} & 64.50 & 8.72 & 28.64 & 28.76 \\
\hline 90 & & 50.88 & 9.74 & 26.96 & 39.77 \\
\hline 120 & & 31.38 & 9.77 & 20.78 & 56.71 \\
\hline
\end{tabular}

Considering the color fastness of the wool fabrics dyed with the spent coffee extract and mordanted with tannic acid, the wool fabrics showed a high level of color fastness to washing (4.5 grade); in contrast, they exhibited somewhat inferior color fastness to light (3-4 grade), as shown in Table 2. However, it was found that the levels of color fastness of the wool fabrics dyed with the spent coffee extract and mordanted with tannic acid may be higher overall than those of fabrics dyed with other natural pigments $[19,20]$.

Table 2. Color fastness of wool fabrics dyed with spent coffee extract and mordanted with 1 wt $\%$ tannic acid aqueous solution.

\begin{tabular}{cccc}
\hline \multicolumn{2}{c}{$\begin{array}{c}\text { Dyeing Conditions } \\
\text { Temperature }\left({ }^{\circ} \mathbf{C}\right)\end{array}$} & $\begin{array}{c}\text { Color Change to Washing } \\
\text { (Grade) }\end{array}$ & $\begin{array}{c}\text { Color Change to Light } \\
\text { (Grade) }\end{array}$ \\
\hline \multirow{3}{*}{90} & 30 & $4-5$ & 3 \\
& 60 & $4-5$ & $3-4$ \\
& 90 & $4-5$ & $3-4$ \\
60 & 120 & $4-5$ & $3-4$ \\
\hline 90 & 60 & $4-5$ & $2-3$ \\
120 & & $4-5$ & $3-4$ \\
\end{tabular}




\subsection{Mechanical Properties of the Wool Fabrics Dyed with the Spent Coffee Extract}

Shrinkage of the wool fabrics occurred through the dyeing and mordanting process, as shown in Table 3. The shrinkage became intensified as the dyeing condition became progressively harsh, i.e. higher temperature and longer time of the dyeing process. In particular, significant shrinkage of the wool fabrics was induced by high-temperature dyeing. The mechanical strength of the wool fabrics dyed with the spent coffee extract and mordanted with tannic acid also depreciated drastically after the high-temperature dyeing at $120^{\circ} \mathrm{C}$. Considering the color appearance and mechanical properties of the wool fabrics dyed with the spent coffee extract, it was discovered that the dyeing process at $90{ }^{\circ} \mathrm{C}$ for 90 min would be optimal conditions for wool fabrics.

Table 3. Shrinkage and tensile strength of wool fabrics dyed with spent coffee extract and mordanted with $1 \mathrm{wt} \%$ tannic acid aqueous solution.

\begin{tabular}{|c|c|c|c|c|c|c|}
\hline \multicolumn{2}{|c|}{ Dyeing Conditions } & \multirow{2}{*}{ Warp } & \multirow{2}{*}{ Weft } & \multirow{2}{*}{$\begin{array}{l}\text { Fabric } \\
\text { Count }\end{array}$} & \multirow{2}{*}{$\begin{array}{c}\text { Shrinkage } \\
(\%)\end{array}$} & \multirow{2}{*}{$\begin{array}{c}\text { Tensile } \\
\text { Strength }(\mathbf{N})\end{array}$} \\
\hline Temperature $\left({ }^{\circ} \mathrm{C}\right)$ & Time (min) & & & & & \\
\hline \multicolumn{2}{|c|}{ Untreated } & 60 & 48 & 2880 & 0 & 117 \\
\hline \multicolumn{2}{|c|}{ Only mordanted } & 60 & 49 & 2940 & 2.04 & 116 \\
\hline \multirow{4}{*}{90} & 30 & 62 & 50 & 3100 & 7.10 & 122 \\
\hline & 60 & 63 & 50 & 3150 & 8.57 & 123 \\
\hline & 90 & 63 & 50 & 3150 & 8.57 & 126 \\
\hline & 120 & 62 & 51 & 3162 & 8.92 & 123 \\
\hline 60 & \multirow{3}{*}{60} & 61 & 50 & 3050 & 5.57 & 125 \\
\hline 90 & & 63 & 50 & 3150 & 8.57 & 123 \\
\hline 120 & & 73 & 61 & 4453 & 35.32 & 76 \\
\hline
\end{tabular}

\subsection{Functional Properties of the Wool Fabrics Dyed with the Spent Coffee Extract}

Tables 4 and 5 show the antibacterial activities of the wool fabrics dyed with the spent coffee extract and mordanted with tannic acid. Overall, they showed significant antibacterial activities against K. pneumoniae, a Gram-negative bacterium, as well as against S. aureus, a Gram-positive bacterium. The effects of dyeing time and dyeing temperature were not significant. However, the wool fabric dyed with spent coffee extract but without mordanting shows insufficient antibacterial ability particularly to K. pneumoniae, as shown in Table 4 (dyeing time $90^{*}$ ). Therefore, it was found that the antibacterial activities of the wool fabrics dyed with the spent coffee extract were dramatically enhanced by mordanting with tannic acid following the dyeing process.

Table 4. Antibacterial activity of wool fabrics dyed with spent coffee extract at $90{ }^{\circ} \mathrm{C}$ as a function of dyeing time (all dying samples were mordanted with $1 \mathrm{wt} \%$ tannic acid aqueous solution except $90^{*}$ sample).

\begin{tabular}{ccc}
\hline Dyeing Time (min) & Reduction $\%$ of S. aureus & Reduction $\%$ of K. pneumoniae \\
\hline Pristine wool & 28.2 & 32.5 \\
30 & 99.2 & 93.1 \\
60 & 99.7 & 97.5 \\
90 & 99.7 & 99.6 \\
$90 *$ & 76.5 & 43.6 \\
120 & 99.6 & 96.2 \\
\hline \multicolumn{2}{r}{} \\
\hline
\end{tabular}

Tables 6 and 7 show the antioxidant activities of the wool fabrics dyed with the spent coffee extract and mordanted with tannic acid. All the wool fabrics dyed with the spent coffee extract and mordanted with tannic acid showed antioxidant capacity greater than $93 \%$, and the activities were increased by a small amount with increased dyeing temperature (Table 7). However, it was observed 
that the antioxidant capacity is also primarily attributed to mordanting. This is because a significant amount of phenolic compounds were attached to the wool fibers via the mordanting process. Phenolic compounds are found in many plants and are known to possess diverse health-promoting effects such as antimelanogenic, antioxidant, antineoplastic, and bacteriostatic properties [21-23]. It was reported that chlorogenic acid is the major phenolic component in spent coffee extract, and gallic acid might be abundant in the mordanting solution. Additionally, the non-phenolic compounds in coffee extracts, such as caffeine and melanoidins, can also contribute to the antioxidant activity and scavenging of hydroxyl radicals (a type of highly active reactive oxygen species (ROS)) [24].

Table 5. Antibacterial capacity of wool fabrics dyed with spent coffee extract for $60 \mathrm{~min}$ as a function of dyeing temperature (all dying samples were mordanted with $1 \mathrm{wt} \%$ tannic acid aqueous solution).

\begin{tabular}{ccc}
\hline Dyeing Temperature $\left({ }^{\circ} \mathbf{C}\right)$ & Reduction $\%$ of S. aureus & Reduction $\%$ of K. pneumoniae \\
\hline Pristine wool & 28.2 & 32.5 \\
60 & 99.6 & 94.1 \\
90 & 99.7 & 97.5 \\
120 & 99.9 & 99.2 \\
\hline
\end{tabular}

Table 6. Antioxidant activity of wool fabrics dyed with spent coffee extract at $90{ }^{\circ} \mathrm{C}$ as a function of dyeing time (all dying samples were mordanted with $1 \mathrm{wt} \%$ tannic acid aqueous solution except $90^{*}$ sample).

\begin{tabular}{cc}
\hline Dyeing Time (min) & DPPH Scavenging Activity (\%) \\
\hline Pristine Wool & 59.65 \\
30 & 94.28 \\
60 & 94.46 \\
90 & 94.83 \\
$90^{*}$ & 59.65 \\
120 & 94.68 \\
\hline
\end{tabular}

${ }^{*}$ Wool fabrics dyed with spent coffee extract but not mordanted.

Table 7. Antioxidant ability of wool fabrics dyed with spent coffee extract for $60 \mathrm{~min}$ as a function of dyeing temperature (all dying samples were mordanted with $1 \mathrm{wt} \%$ tannic acid aqueous solution).

\begin{tabular}{cc}
\hline Dyeing Temperature $\left({ }^{\circ} \mathbf{C}\right)$ & DPPH Scavenging Activity (\%) \\
\hline Pristine wool & 59.65 \\
60 & 93.59 \\
90 & 94.30 \\
120 & 95.13 \\
\hline
\end{tabular}

\section{Conclusions}

Wool fabrics were dyed with spent coffee extract and mordanted with tannic acid to generate functionalized and colored textiles and to recycle spent coffee grounds, which are a major component of bio-waste. The spent coffee extract was simply prepared by using a manual espresso machine, and the extract contained many functional compounds, including phenolic compounds (gallic acid and chlorogenic acid) and nitrogenous compounds (trigonelline and caffeine). The spent coffee extract significantly colored wool fabrics brown via the dyeing process, and the coloring effect was enhanced by increasing the dyeing time and temperature. However, dyeing at extremely high temperature was observed to deteriorate the mechanical strength of wool fabrics and, therefore, dyeing at $90{ }^{\circ} \mathrm{C}$ for $90 \mathrm{~min}$ would be the optimal condition for dyeing wool fabrics with spent coffee extract. On the other hand, dyeing with the spent coffee extract alone imparted a limited level of functionality to the fabrics, such as antibacterial activity and antioxidant capacity. However, mordanting with tannic acid after the 
dyeing process could enhance the functionalities of the wool fabrics dyed with spent coffee extract and improve the color fastness of the fabrics to light.

Author Contributions: Conceptualization, K.H.H.; methodology, K.H.H.; validation, K.H.H. and J.B.; formal analysis and investigation, K.H.H.; writing-original draft preparation, K.H.H.; writing—review and editing, J.B.; visualization, K.H.H. and J.B.; project administration and funding acquisition, K.H.H.

Funding: This research was supported by the Basic Science Research Program through the National Research Foundation of Korea (NRF) funded by the Ministry of Science, ICT and Future Planning (NRF-2016R1A1A3A04918760).

Conflicts of Interest: The authors declare no conflict of interest.

\section{References}

1. Jo, J.; Kim, S.; Min, B.; Jung, H.; Han, Y.; Kim, J. Optimization of hot-water extraction condition of bioactive compounds from coffee residue extracts. Korean Chem. Eng. Res. 2017, 55, 358-362. [CrossRef]

2. Yonhap News. Available online: http://m.news.naver.com/read.nhn?mode=LSD\&sid1=101\&sid2=310\& oid=001\&aid=0009899801 (accessed on 18 February 2018).

3. Maekyung Economy News. Available online: http://news.mk.co.kr/newsRead.php?year=2016\&no=865578 (accessed on 18 February 2018).

4. Lee, K.O.; Kim, H.J.; Lee, H.J.; Hyeon, S.J. Up-cycling natural dyeing using coffee sludge: Dyeability study of coffee pigment. Fiber Technol. Ind. 2017, 21, 82-92.

5. Mussatto, S.I.; Ballesterols, L.F.; Martins, S.; Teixeira, J.A. Extraction of antioxidant phenolic compounds from spent coffee grounds. Sep. Purif. Technol. 2011, 83, 173-179. [CrossRef]

6. Koh, E.; Hong, K.H. Preparation and properties of cotton fabrics finished with spent coffee extract. Cellulose 2017, 24, 5225-5232. [CrossRef]

7. Koh, E.; Hong, K.H. Preparation and properties of wool fabrics dyed with spent coffee ground extract. Text. Res. J. 2018, 89, 13-19. [CrossRef]

8. Ibrahim, N.A.; El-Zairy, W.M.; El-Zairy, M.R.; Ghazal, H.A. Enhancing the UV-protection and antibacterial properties of polyamide-6 fabric by natural dyeing. Text. Light Ind. Sci. Technol. 2013, 2, 36-41.

9. Rahman Bhuiyan, M.A.; Ali, A.; Islam, A.; Hannan, M.A.; Fijul Kabir, S.M.; Islam, M.N. Coloration of polyester fiber with natural dye henna (Lawsonia inermis L.) without using mordant: A new approach towards a cleaner production. Fash. Text. 2018, 5, 1-11. [CrossRef]

10. Singleton, V.L.; Rossi, J.A. Colorimetry of total phenolics with hosphomolybdic-phosphotungstic acid reagents. Am. J. Enol. Vitic. 1956, 16, 144-158.

11. Broadhust, R.B.; Jones, W.T. Analysis of condensed tannins using acidified vanillin. J. Sci. Food Agric. 1978, 29, 788-794. [CrossRef]

12. Han, J.; Weng, X.C.; Bi, K.S. Antioxidants from a Chinese medicinal herb—Lithospermum erythrorhizon. Food Chem. 2008, 106, 2-10. [CrossRef]

13. Almeida, A.A.P.; Naghetini, C.C.; Santos, V.R.; Antonio, A.G.; Farah, A.; Glória, M.B.A. Influence of natural coffee compounds, coffee extracts and increased levels of caffeine on the inhibition of Streptococcus mutans. Food Res. Int. 2012, 49, 459-461. [CrossRef]

14. Hsieh, S.H.; Huang, Z.K.; Huang, Z.Z.; Tseng, Z.S. Antimicrobial and physical properties of woolen fabrics cured with citric acid and chitosan. J. Appl. Polym. Sci. 2004, 94, 1999-2007. [CrossRef]

15. Lekha, P.K.; Lonsane, B.K. Production and application of tannin acyl hydrolase: State of the art. Adv. Appl. Microbiol. 1997, 44, 215-260. [PubMed]

16. Chung, K.T.; Wong, T.Y.; Wei, C.I.; Huang, Y.W.; Lin, Y. Tannins and human health: A review. Crit. Rev. Food Sci. Nutr. 1998, 38, 421-464. [CrossRef]

17. Hong, K.H. Effects of tannin mordanting on coloring and functionalities of wool fabrics dyed with spent coffee grounds. Fash. Text. 2018, 5, 1-11. [CrossRef]

18. Moreira, A.S.P.; Nunes, F.M.; Dominguesa, M.R.; Coimbra, M.A. Coffee melanoidins: Structures, mechanisms of formation and potential health impacts. Food Funct. 2012, 3, 903-915. [CrossRef] [PubMed]

19. Hong, K.H. Preparation and properties of cotton and wool fabrics dyed by black rice extract. Text. Res. J. 2015, 85, 1875-1883. [CrossRef] 
20. Koh, E.; Hong, K.H. Functional fabric treatment using tannic acid and extract from purple-fleshed sweet potato. Text. Res. J. 2017, 87, 790-798. [CrossRef]

21. Almeida, A.A.; Farah, A.; Sylva, D.A.; Nunan, E.A.; Gloria, M.B. Antibacterial activity of coffee extracts and selected coffee chemical compounds against enterobacteria. J. Agric. Food Chem. 2006, 54, 8738-8743. [CrossRef]

22. Nohynek, L.J.; Alakomi, H.L.; Kähkönen, M.P.; Heinonen, M.; Helander, I.M.; Oksman-Caldentey, K.M.; Puupponen-Pimiä, R.H. Berry phenolics: Antimicrobial properties and mechanisms of action against severe human pathogens. Nutr. Cancer 2006, 54, 18-32. [CrossRef]

23. Shin, Y.; Choi, M.; Yoo, D.I. Eco-friendly indigo reduction using bokbunja (Rubus coreanus Miq.) sludge. Fash. Text. 2016, 1, 1-8. [CrossRef]

24. Shi, X.; Dalal, N.S.; Jain, A.C. Antioxidant behaviour of caffeine: Efficient scavenging of hydroxyl radicals. Food Chem. Toxicol. 1991, 29, 1-6. [CrossRef]

(C) 2019 by the authors. Licensee MDPI, Basel, Switzerland. This article is an open access article distributed under the terms and conditions of the Creative Commons Attribution (CC BY) license (http://creativecommons.org/licenses/by/4.0/). 